\title{
Necessidade hídrica do meloeiro irrigado com água de diferentes salinidades e cultivado com ou sem cobertura do solo ${ }^{1}$
}

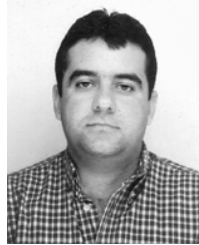

Francisco A. S. B. de Medeiros ${ }^{2}$, José F. de Medeiros ${ }^{3}$, Marcelo C. de C. Silva ${ }^{4}$, Leonardo P. Alves ${ }^{3}$, Tonny H.de Souza ${ }^{5}$ \& Sérgio L. A. Levien ${ }^{3}$

\footnotetext{
Trabalho financiado com recursos do Convênio SINTEC/FUNPEC 008/2001 - Irrigação e Drenagem

${ }^{2}$ NOLEM Comercial Importadora e Exportadora LTDA, BR 110, Km 33,8, Bairro Abolição III, CEP 59616-280, Mossoró, RN (Foto)

${ }^{3}$ Coordenadoria de Pesquisa e Pós-Graduação/ESAM, CEP 59625-900, Mossoró, RN. E-mail: jfmedeir@esam.br; slevien@esam.br

4 Doutorando em Fitotecnia/UFV, CEP 36571-000, Viçosa, MG. E-mail: mdecastro70@hotmail.com

5 Mestrando em Fitotecnia, ESAM. E-mail: leonardo@porpino.com
}

Protocolo 140 - 5/9/2003 - Aprovado em 17/8/2004

\begin{abstract}
Resumo: A necessidade hídrica das culturas pode ser estimada a partir da evapotranspiração de referência (ETo) e do coeficiente de cultura (kc). Com o objetivo de se estimar a necessidade hídrica de duas cultivares de melão (Gold mine e Trusty) cultivadas com e sem cobertura do solo com filme de polietileno e irrigadas por gotejamento com água de diferentes salinidades $(1,2,2,5$ e 4,4 $\mathrm{dS}^{-1}$ ) instalou-se um experimento no município de Mossoró, RN, em um Argissolo Vermelho Amarelo. Para se obter a necessidade hídrica da cultura, realizou-se o balanço hídrico nas parcelas, obtendo-se os coeficientes de cultura. Para medir a variação de armazenamento de água no perfil do solo e o fluxo subterrâneo, foram instaladas baterias com três tensiômetros em cada parcela de dois blocos experimentais. A lâmina de irrigação foi estimada pela metodologia FAO e ajustada de acordo com o monitoramento da umidade do solo. A água de maior salinidade diminuiu a evapotranspiração do meloeiro em $14 \%$, a cobertura de solo reduziu em $18 \%$ e a cultivar Trusty evapotranspirou $11 \%$ a menos que a Gold mine. O balanço hídrico permitiu que se estimassem os coeficientes de cultura do meloeiro para diferentes salinidades, cobertura de solo e cultivares.
\end{abstract}

Palavras-chave: umidade do solo, coeficiente de cultura, mulch

\section{Water requirements of melon irrigated with different water salinities, cultivated with and without mulching}

\begin{abstract}
The water requirement of the crops can be estimated from the reference evapotranspiration (ETo) and crop coefficients (kc). Aiming to estimate the water requirement of two cultivars of melon (Gold mine and Trusty) cultivated with and without soil covering with polyethylene film and irrigated by trickle irrigation with water of different salinities (1.2, 2.5 and $4.4 \mathrm{dS} \mathrm{m}^{-1}$ ), an experiment was installed in the municipal district of Mossoró, RN, in an Alfissol. To obtain the water requirement of the crop the water balance was accomplished in the plots, obtaining the crop coefficients. To obtain the variation in water storage in the soil profile and the subsurface flow three tensiometers were installed in each plot of two experimental blocks. The irrigation was estimated daily using ETo and kc recommended by FAO and was adjusted in agreement with the monitoring of the soil moisture. In water of higher salinity the evapotranspiration of the melon plant was reduced by $14 \%$; the soil covering reduced it by $18 \%$; and the cultivar Trusty evapotranspirated $11 \%$ less than the Gold mine. The water balance allow to estimate the crop coefficient of melon plants for different salinities, soil covering and cultivars.
\end{abstract}

Key words: soil moisture, crop coefficient, mulch

\section{INTRODUÇÃO}

O incremento de áreas irrigadas no mundo tem permitido se aumentar a produtividade das áreas cultivadas e o suprimento de alimentos para a população mundial; entretanto, a irrigação tem sido responsável por $70 \%$ do consumo da água no mundo.

Para se resolver esta problemática, é conveniente saber que a cultura necessita de determinada quantidade de água que 
deve ser aplicada em momentos oportunos. Quando o volume de água e a freqüência de aplicação são determinados por fatores relacionados ao solo, clima e característica própria da planta está se realizando irrigação.

A quantidade de água que se perde em uma área cultivada por evaporação da superfície do solo e por transpiração da planta, denomina-se necessidade hídrica (Doorenbos \& Kassam, 1994; Allen et al., 1998).

A irrigação localizada é o método mais utilizado na fruticultura irrigada no Rio Grande do Norte e, em outros Estados brasileiros e se caracteriza por se aplicar, pontualmente, pequenas quantidades de água ao pé da planta, quantidades ideais para seu bom desenvolvimento, variando os volumes com as fases fenológicas e com a demanda evapotranspirativa. $\mathrm{O}$ umedecimento de apenas uma porção da superfície do solo reduz substancialmente a evaporação da mesma, principalmente quando a cultura ainda não cobriu a superfície do solo (Allen et al., 1998).

O aumento das áreas irrigadas tem levado ao uso de água de qualidade inferior, provocando problemas de salinidade. Segundo Ayers \& Westcot (1999), quanto maior o conteúdo de sais no solo, maior será o esforço que a planta terá para absorver a água; assim, ocorre a diminuição no uso consuntivo da planta à medida que cresce a concentração de sais na região da zona radicular das culturas (Allen et al., 1998; Medeiros, 1998).

A salinização dos solos é mais comum nas regiões áridas e semi-áridas, onde a água de irrigação, além de satisfazer a necessidade hídrica da cultura, é responsável por manter o balanço de sais na zona radicular da cultura pelo uso de uma fração de lixiviação (Rhoades et al., 2000).

Para se fazer um uso melhor da água é necessário, também, realizar o monitoramento de umidade a partir do qual se aplica a quantidade correta que a planta requer, evitando desperdícios.

A cobertura do solo com filme plástico (mulch) em espécies olerícolas torna-se prática importante porque, além de controlar o balanço de radiação na superfície do solo, proporciona maior desenvolvimento vegetativo e produtividade (Silva, 2002), evita o desenvolvimento de ervas daninhas (Ferreira, 2001), aumenta a tolerância ao uso de água de baixa qualidade na irrigação (Nascimento et al., 2000) e promove repelência a insetos (Ferreira, 2001), além de diminuir a evapotranspiração das culturas (Allen et al., 1998).

O mulch, por eliminar a evaporação da superfície do solo, permite à planta absorver a água desta camada, região esta de menor concentração de sais e onde chegam primeiro os fertilizantes aplicados via água de irrigação.

Assim, objetivou-se, com este trabalho, estimar a necessidade hídrica da cultura do melão irrigado, através do balanço hídrico, utilizando-se água com diferentes salinidades e cobertura do solo.

\section{MATERIAL E MÉTODOS}

O experimento foi conduzido com duas cultivares de melão, os híbridos "Gold mine" e "Trusty", respectivamente, dos tipos amarelo e cantaloupe. O ensaio foi conduzido entre dezembro de 2000 e fevereiro de 2001, no município de Mossoró, RN $\left(5^{\circ} 12^{\prime} \mathrm{S}, 37^{\circ} 12^{\prime} \mathrm{W}\right.$ e $30 \mathrm{~m}$ de altitude). O solo da área experimental é um Podzólico Vermelho Amarelo latossólico, atualmente classificado de acordo com EMBRAPA (1999) como Argissolo Vermelho-Amarelo.

Os tratamentos consistiram na utilização de três níveis de salinidade da água de irrigação $\left(\mathrm{S} 1=1,2 \mathrm{dS} \mathrm{m}^{-1} ; \mathrm{S} 2=2,5 \mathrm{dS} \mathrm{m}^{-1} \mathrm{e}\right.$ $\mathrm{S} 3=4,4 \mathrm{dS} \mathrm{m}^{-1}$ ), duas cultivares (Gold mine e Trusty) e duas condições de cobertura do solo (sem e com cobertura de plástico dupla face - preto/prateado). Utilizou-se o delineamento experimental em blocos ao acaso, em esquema fatorial $3 \times 2 \times 2$, com quatro repetições, sendo as parcelas experimentais formadas por três fileiras de $6 \mathrm{~m}$, com 24 plantas por fileira. A água de menor salinidade foi obtida pela mistura da água de poços do arenito Assu $\left(\mathrm{CE}=0,6 \mathrm{dS} \mathrm{m}^{-1}\right)$ e do calcário Jandaíra $\left(\mathrm{CE}=2,5 \mathrm{dS} \mathrm{m}^{-1}\right)$, que corresponde à água $\mathrm{S} 2$. A água $\mathrm{S} 3$ foi obtida pela adição de $\mathrm{NaCl}$ à água do poço calcário $(0,9$ a $\left.1,0 \mathrm{~g} \mathrm{~L}^{-1}\right)$.

Utilizou-se, para cada água, um sistema de irrigação por gotejamento com emissores de $2,3 \mathrm{~L} \mathrm{~h}^{-1}$ e coeficiente de variação de vazão determinado no campo inferior a $5 \%$, distanciados $0,50 \mathrm{~m}$ na linha, e cada linha disposta em ziguezague em cada parcela.

A evapotranspiração da cultura (ETc) para fins de manejo da irrigação, foi estabelecida a partir da estimativa da evapotranspiração de referência, que foi realizada pelo método de Penman-Monteith, através de dados climáticos obtidos na estação automática da Escola Superior de Agricultura de Mossoró - ESAM, distante $10 \mathrm{~km}$ da área experimental; utilizaram-se os coeficientes de cultivo $(\mathrm{kc})$ propostos pela FAO (Allen et al., 1998), aplicando-se a metodologia do kc dual. Adotaram-se valores de $\mathrm{kcb}$ (coeficiente de cultura basal) para as fases inicial, intermediária e final de 0,$15 ; 1,0$ e 0,7 , respectivamente, para o tratamento considerado padrão (cultivar Gold mine, água S1 e na ausência de mulch). A lâmina bruta de irrigação foi obtida acrescentando-se $10 \%$ à ETc estimada. Para os outros tratamentos, foram aplicadas reduções de lâminas, usando-se o método da tentativa e acerto, conforme o monitoramento da umidade do solo e a fração de solo coberta pela cultura.

A freqüência de irrigação foi estabelecida para o tratamento padrão, não permitindo que a tensão da água no solo fosse superior a $30 \mathrm{kPa}$, o que proporcionou freqüência de uma e duas vezes ao dia. Os demais tratamentos seguiram esta freqüência.

A estimativa da evapotranspiração real para cada tratamento foi feita pelo balanço hídrico ajustado para irrigação localizada (Medeiros, 1998) para intervalos de tempo semanais, representada pela Eq. 1.

$$
\mathrm{ET}=\mathrm{I}-\mathrm{Q}_{\mathrm{z}} \cdot \mathrm{FM}+\Delta \mathrm{S}_{\mathrm{z}} \cdot \mathrm{FM}
$$

em que:

ET - evapotranspiração, $\mathrm{mm}$

I - lâmina de irrigação, $\mathrm{mm}$

$\mathrm{Q}_{\mathrm{z}}$ - fluxo de água na profundidade " $\mathrm{z}$ ", assumida como $0,45 \mathrm{~m}, \mathrm{~mm}$

FM - fator de molhamento, que representa a razão entre a 
área média molhada e a área total ocupada pelo emissor no decorrer do ciclo, de acordo com Keller \& Bliesner (1990)

$\Delta \mathrm{S}_{\mathrm{z}}$ - variação de armazenamento para a profundidade " $\mathrm{z}$ ", no intervalo de tempo, $\mathrm{mm}$

Para a realização do balanço hídrico foram instaladas baterias de três tensiômetros (profundidades de 15, 30 e $45 \mathrm{~cm}$ ) em todas as parcelas de dois blocos experimentais. Diariamente foram realizadas três medidas de tensão da água no solo (às 7:00, 11:00 e 16:00 h). A variação de armazenamento no período de cada semana foi obtida pela diferença entre a lâmina de água média armazenada até a profundidade " $z$ " entre dias constantes da semana, tomando-se a média de três dias consecutivos, para reduzir os erros. A lâmina de cada irrigação foi obtida dividindo-se o volume de água aplicado à parcela pela área ocupada pelas plantas na parcela. A curva de condutividade hidráulica do solo da área foi obtida pelo método do perfil instantâneo, em duas bacias de aproximadamente 9 $\mathrm{m}^{2}$, conforme metodologia descrita em Libardi (1999). A curva $\mathrm{K}(\mathrm{h})$, com $h$ sendo a tensão da água no solo, em $\mathrm{kPa}$, foi $\mathrm{K}(\mathrm{h})=$ $7,78 \mathrm{~h}^{1,69}$. O fator de molhamento obtido de medidas realizadas semanalmente em diferentes tratamentos, abrindo-se valetas transversais às fileiras por não ter apresentado variações significativas, foi assumido como sendo a média, que foi de 0,40 .

Para o ajuste da curva do kc ao longo do tempo para as diferentes condições, adotou-se um ajuste dos pontos para as quatro fases fenológicas; assim, para a fase I assumiu-se a média dos kc estimados das $2^{\mathrm{a}}, 3^{\mathrm{a}}$ e $4^{\mathrm{a}}$ semanas (primeiras semanas); para a fase II ajustou-se uma equação de regressão para os kc das $4^{\mathrm{a}}, 5^{\mathrm{a}}, 6^{\mathrm{a}}$ e $7^{\mathrm{a}}$ semanas; para a fase III a média das $7^{\mathrm{a}}$ e $8^{\mathrm{a}}$ semana e, para a fase IV, ajustou-se uma equação de regressão dos pontos das $8^{\mathrm{a}}, 9^{\mathrm{a}}$ e $10^{\mathrm{a}}$ semanas. A curva foi traçada definindo-se limites para cada fase fenológica, pela interseção das retas.

\section{RESULTADOS E DISCUSSÃO}

A irrigação com água de diferentes salinidades proporcionou, da quinta à sétima semana após o plantio, diferença significativa entre os valores de potencial matricial de água no solo, com maiores valores à medida que a salinidade da água aumentava; entretanto, os valores ainda permaneceram próximos do potencial para a capacidade de campo, $\Psi_{\mathrm{m}}=-10$ $\mathrm{kPa}$ (Figura 1A) o não implica no fato de que a lâmina aplicada esteja abaixo da necessidade hídrica mas, devido à maior evapotranspiração e, conseqüentemente, maior retirada de água pelas plantas no tratamento menos salino, comparado aos tratamentos mais salinos, e a redistribuição de água não acompanhando a mesma velocidade da retirada de água pela cultura levou, possivelmente, a este menor potencial matricial. Costa (1999) verificou comportamento semelhante para os valores de potencial matricial entre irrigações com água de salinidades diferentes.

Comparando-se o potencial matricial entre as parcelas cobertas e as descobertas (Figura 1B) concluiu-se que as diferenças são mínimas, indicando que as lâminas de irrigação foram bem ajustadas. Quanto às cultivares entre as sexta e oitava semanas, a Gold mine proporcionou menores valores de potencial matricial (Figura 1C), o que pode ser explicado pela maior demanda hídrica desta cultivar, permitindo que a redistribuição de água no perfil não possa ocorrer na mesma velocidade em que a água é retirada do solo. Embora exista diferença entre o potencial matricial, se esta for convertida em umidade a diferença absoluta será inferior a 1\%, conforme dados da curva de retenção do solo.

A

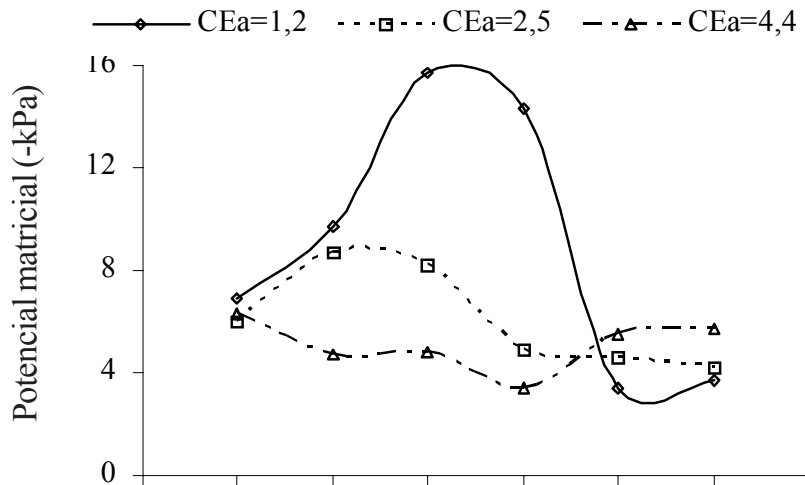

B.

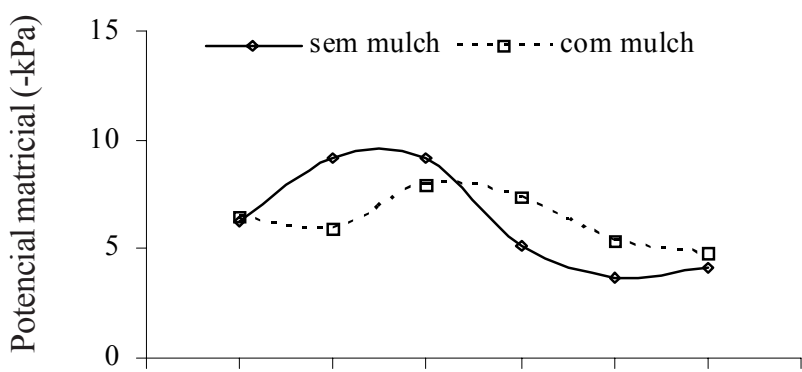

C.

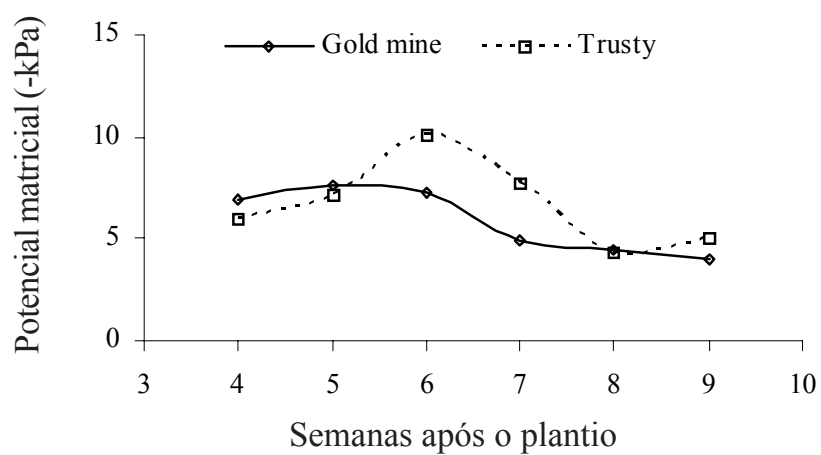

Figura 1. Potencial matricial da água no solo, na profundidade de 0 a $45 \mathrm{~cm}$ ao longo do ciclo sob diferentes salinidades da água de irrigação (A), com ou sem mulch (B) e de duas cultivares de melão $(\mathrm{C})$

Os dados referentes aos componentes do balanço hídrico (Tabela 1) indicam que o armazenamento de água no perfil apresentou poucas variações, seja entre os tratamentos ou entre os períodos estudados; quanto à percolação profunda, os valores totais variaram entre 5 e $10 \%$ da lâmina de irrigação aplicada, valor próximo dos $10 \%$ previstos. Considerando-se a evapotranspiração real do melão nos diferentes tratamentos, constata-se que entre os níveis salinos, apenas o maior nível proporcionou redução significativa, da ordem de 14\%, quando comparado com o tratamento menos salino; o solo com mulch 
Tabela 1. Valores dos componentes do balanço hídrico para diferentes salinidades da água de irrigação, solo com cobertura (mulch) e sem cobertura e para duas cultivares e da evapotranspiração de referência, em diferentes períodos ao longo do ciclo do melão

\begin{tabular}{|c|c|c|c|c|c|c|c|c|c|c|}
\hline \multirow{2}{*}{$\begin{array}{c}\text { Níveis dos } \\
\text { Fatores }\end{array}$} & \multicolumn{10}{|c|}{ Dias Após o Plantio } \\
\hline & $8 *$ & 15 & 22 & 29 & 36 & 43 & 50 & 57 & 64 & 71 \\
\hline \multicolumn{11}{|c|}{ Armazenamento (mm) } \\
\hline S1 & 24 & 24 & 24 & 29 & 21 & 23 & 24 & 26 & 26 & 26 \\
\hline S2 & 23 & 23 & 23 & 30 & 22 & 26 & 27 & 29 & 28 & 28 \\
\hline S3 & 25 & 25 & 25 & 30 & 26 & 27 & 30 & 31 & 30 & 30 \\
\hline Sem mulch & 26 & 26 & 26 & 31 & 22 & 26 & 28 & 29 & 27 & 27 \\
\hline Com mulch & 23 & 23 & 23 & 29 & 24 & 24 & 26 & 29 & 29 & 29 \\
\hline Gold mine & 25 & 25 & 25 & 30 & 25 & 28 & 28 & 31 & 29 & 29 \\
\hline Trusty & 24 & 24 & 24 & 29 & 21 & 23 & 26 & 27 & 27 & 27 \\
\hline \multicolumn{11}{|c|}{ Percolação Profunda $\left(\mathrm{mm} \mathrm{semana}^{-1}\right)$} \\
\hline S1 & 0,8 & 0,8 & 0,7 & 1,0 & 1,2 & 1,7 & 2,0 & 2,2 & 2,2 & 12,6 \\
\hline S2 & 0,2 & 0,2 & $-0,6$ & 1,0 & 2,4 & 2,5 & 2,4 & 1,9 & 1,9 & 12,0 \\
\hline S3 & 1,5 & 1,5 & 1,3 & 1,7 & 2,5 & 2,9 & 3,3 & 2,4 & 2,4 & 19,4 \\
\hline Sem mulch & 0,8 & 0,8 & 0,2 & 1,3 & 2,0 & 2,4 & 2,8 & 2,0 & 2,0 & 14,3 \\
\hline Com mulch & 0,9 & 0,9 & 0,7 & 1,1 & 2,0 & 2,4 & 2,4 & 2,4 & 2,4 & 15,1 \\
\hline Gold mine & 1,7 & 1,7 & 1,3 & 2,1 & 2,9 & 2,9 & 2,9 & 2,7 & 2,7 & 20,8 \\
\hline Trusty & 0,0 & 0,0 & $-0,4$ & 0,4 & 1,1 & 1,9 & 2,2 & 1,7 & 1,7 & 8,6 \\
\hline \multicolumn{11}{|c|}{ Irrigação (mm semana $^{-1}$ ) } \\
\hline S1 & 11,8 & 8,7 & 12,9 & 17,1 & 31,2 & 38,3 & 38,8 & 26,2 & 24,9 & 209,9 \\
\hline S2 & 11,8 & 8,7 & 12,9 & 17,1 & 30,8 & 37,5 & 37,9 & 24,5 & 22,3 & 203,5 \\
\hline $\mathrm{S} 3$ & 11,8 & 8,7 & 12,9 & 17,1 & 29,7 & 36,0 & 35,0 & 21,7 & 19,9 & 192,8 \\
\hline Sem mulch & 13,1 & 9,8 & 14,1 & 18,5 & 32,7 & 39,5 & 39,3 & 25,3 & 23,7 & 215,9 \\
\hline Com mulch & 10,5 & 7,7 & 11,7 & 15,8 & 28,4 & 35,0 & 35,2 & 22,9 & 21,0 & 188,2 \\
\hline Gold mine & 11,8 & 8,7 & 13,6 & 18,5 & 32,4 & 40,4 & 40,3 & 26,3 & 25,0 & 217,1 \\
\hline Trusty & 11,8 & 8,7 & 12,2 & 15,8 & 28,7 & 34,2 & 34,1 & 21,9 & 19,7 & 187,0 \\
\hline \multicolumn{11}{|c|}{ Evapotranspiração Real da Cultura $\left(\mathrm{mm} \mathrm{semana}^{-1}\right)$} \\
\hline S1 & 11,0 & 7,9 & 7,6 & 23,9 & 28,1 & 35,9 & 34,5 & 25,1 & 22,7 & 196,7 \\
\hline S2 & 11,6 & 8,5 & 6,9 & 24,5 & 24,4 & 34,1 & 35,5 & 24,4 & 20,4 & 190,4 \\
\hline S3 & 10,4 & 7,3 & 6,8 & 19,4 & 26,4 & 29,7 & 31,0 & 21,0 & 17,5 & 169,3 \\
\hline Sem mulch & 12,3 & 9,0 & 8,9 & 25,9 & 26,4 & 35,4 & 37,5 & 26,7 & 21,8 & 203,8 \\
\hline Com mulch & 9,6 & 6,8 & 5,3 & 19,3 & 26,2 & 31,1 & 29,8 & 20,3 & 18,6 & 167,1 \\
\hline Gold mine & 10,1 & 7,0 & 7,4 & 21,8 & 26,2 & 37,3 & 36,6 & 27,0 & 22,3 & 195,9 \\
\hline Trusty & 11,8 & 8,7 & 6,8 & 23,4 & 26,3 & 29,2 & 30,7 & 20,0 & 18,0 & 175,0 \\
\hline ETo $\left(\mathrm{mm} \mathrm{d}^{-1}\right)$ & 5,77 & 5,68 & 5,90 & 5,09 & 6,13 & 5,88 & 6,08 & 5,29 & 6,32 & 364,9 \\
\hline
\end{tabular}

* Por falta de medida na segunda semana, adotaram-se os valores da terceira semana; os valores de percolação profunda, irrigação e evapotranspiração real da cultura referem-se aos periodos de 8 a 14,15 a 21,22 a 28,29 a 35,36 a 42,43 a 49,50 a 56,57 a 63,64 a 70 dias após plantio e do período total

reduziu o consumo hídrico em $18 \%$ e a cultivar Trusty evapotranspirou menos $11 \%$, quando comparada com a Gold mine. Essas variações estão dentre as amplitudes apresentadas por Allen et al. (1998) para tais condições. A menor evapotranspiração da cultura nas condições mais salinas pode ser explicada pela redução no índice de área foliar, que chegou a $15 \%$ a partir de 35 dias.

O coeficiente de cultura foi aproximadamente constante e semelhante entre os níveis salinos da água de irrigação na fase inicial $(0,22)$ crescendo a partir do $23^{\circ}$ dia até o $40^{\circ}$ dia sendo que ao longo desta fase, o kc cresceu mais para a água menos salina, mas não diferiu do kc estimado para a água de salinidade intermediária $\left(2,5 \mathrm{dS} \mathrm{m}^{-1}\right)$ (Figura 2A). A partir dos 53 dias o kc começou a diminuir, chegando a valores entre 0,4 e 0,5 aos 65 dias, com o menor valor para água mais salina. O comportamento do kc apresentou configuração similar à recomendada pela FAO (Allen et al., 1998). A diminuição do kc com a elevação da salinidade pode ser justificada pelo efeito do estresse osmótico, o que reduziu o índice de área foliar e em conseqüência, a evapotranspiração da cultura.

Considerando-se a presença do mulch, o kc foi reduzido ao longo de todo o ciclo da cultura, mas diminuiu a diferença ao final do ciclo (Figura 2B). As diminuições do kc, ao longo do ciclo, ficaram entre 15 e $20 \%$.

Comparando-se os kc médios entre as cultivares (Figura 2C), observa-se que no início do ciclo a Trusty apresentou maior $\mathrm{kc}$ até o $30^{\circ}$ dia passando, a partir daí, o kc da Gold mine a ser superior, atingindo uma diferença de cerca de $18 \%$ para esta cultivar, quando comparada com a Trusty. 
A.

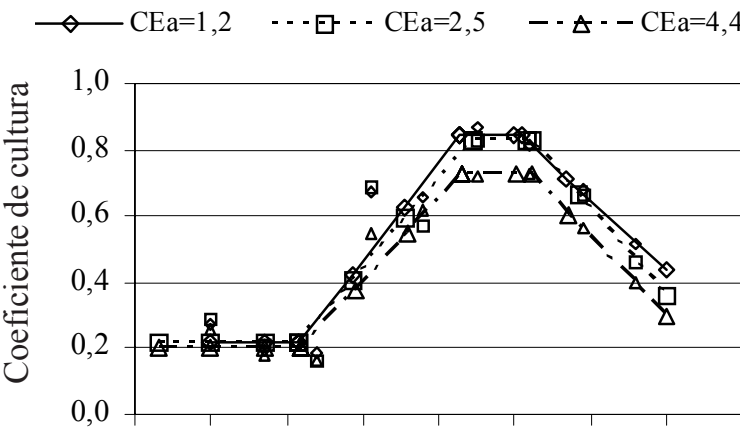

B.

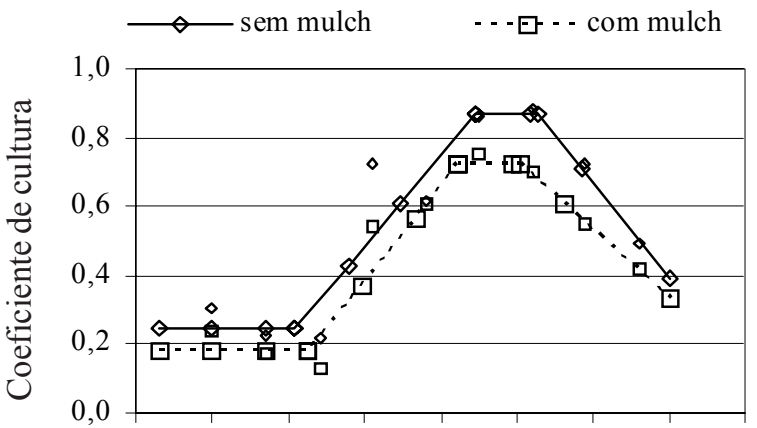

C.

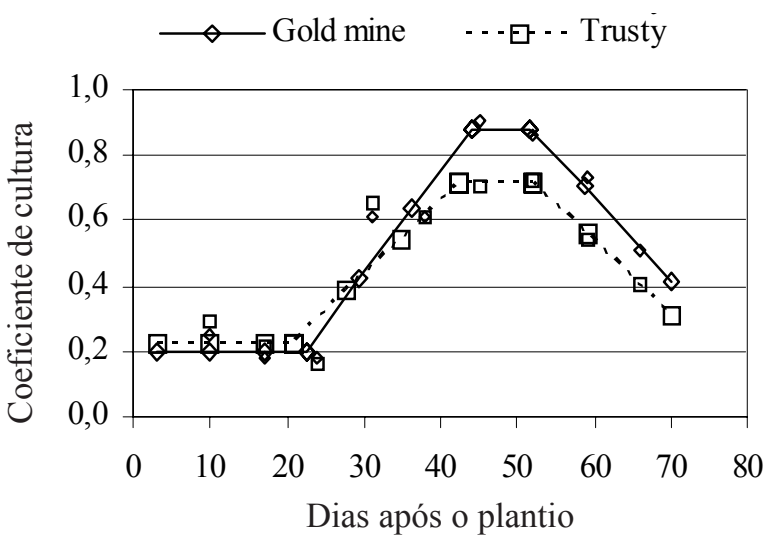

Figura 2. Coeficiente de cultura médio do meloeiro para diferentes salinidades da água de irrigação, cultivado com e sem mulch e para as cultivares Gold mine e Trusty

Ressalta-se que, para serem comparados com os valores tabulados pela FAO (Allen et al., 1998) os valores de kc apresentados na Figura 2, deveriam ser ajustados para umidade relativa mínima do dia (45\%), velocidade do vento de $2 \mathrm{~m} \mathrm{~s}^{-1} \mathrm{e}$ altura da planta de 3,0 m mas, para as condições climáticas em que foi realizado o estudo, o valor do ajuste está entre $0,01 \mathrm{e}$ 0,02 , e pode ser desprezado.

\section{CONCLUSÕES}

1. A evapotranspiração do meloeiro diminuiu quando a salinidade da água de irrigação cresceu entre 1,2 e 4,4 $\mathrm{dS} \mathrm{m}^{-1}$.

2. A cobertura de solo com mulch de polietileno proporcionou redução na necessidade hídrica.
3. As cultivares de melão apresentaram comportamento hídrico distinto nas segunda, terceira e quarta fases fenológicas que, em média, ficou entre os $23^{\circ}$ e $40^{\circ}, 40^{\circ}$ e $53^{\circ}$ e $53^{\circ}$ e $70^{\circ}$ dias, respectivamente.

4. O balanço hídrico permitiu se estimar os coeficientes de cultura do meloeiro para diferentes salinidades, cobertura de solo e cultivares.

\section{LITERATURA CITADA}

Allen, R.G.; Pereira, L.S.; Raes, D.; Smith,M. Crop evapotranspiration: guidelines for computing crop water requirements. Rome: FAO, 1998, 297p. FAO. Irrigation and Drainage Paper, 56

Ayers, R.S.; Westcot, D.W. A qualidade da água na agricultura. 2.ed. Campina Grande: UFPB, 1999. 153p. FAO. Estudos de Irrigação e Drenagem, 29 revisado

Costa, M.C. Efeito de diferentes lâminas de água com dois níveis de salinidade na cultura do meloeiro. Botucatu: UNESP, 1999. 115p. Tese Doutorado

Doorenbos, J.; Kassam, A.H. Efeito da água no rendimento das culturas. Campina Grande: UFPB, 1994. 306p.

EMBRAPA. Centro Nacional de Pesquisa de Solos. Sistema brasileiro de classificação de solos. Brasília: Embrapa Produção de Informação; Rio de Janeiro: Embrapa Solos, 1999. 412p.

Ferreira, R.L.F. Produção e qualidade de melão cultivado sob condições climáticas resultantes de diferentes coberturas de solo e métodos de plantio. Mossoró: ESAM, 2001. 63p. Dissertação Mestrado

Keller, J.; Bliesner, R.D. Sprinkle and trickle irrigation. New York: van Nostrand Reinhold, 1990. 652p.

Libardi, P.L. Dinâmica da água no solo. 2.ed. Piracicaba, 1999. $501 \mathrm{p}$.

Medeiros, J.F. de. Manejo da água de irrigação salina em estufa cultivada com pimentão. Piracicaba: ESALQ, 1998. 152p. Tese Doutorado

Nascimento, I.B. do; Medeiros, K.F.; Miranda, N.O.; Silva, M.C.C.; Alves, L.A.; Lisboa, R.A.; Silva Júnior, M.J. da. Desenvolvimento vegetativo do melão cultivado sob diferentes intensidades de preparo de solo com e sem mulching. In: Congresso Brasileiro de Engenharia Agrícola, 29, Fortaleza 2000, Anais... Fortaleza: SBEA, 2000. CD-Rom

Rhoades, J.D.; Kandiah, A.; Mashali, A.M. Uso de águas salinas para produção agrícola. Campina Grande: UFPB, 2000. 117p. FAO. Estudos Irrigação e Drenagem, 48.

Silva, M.C.C. Crescimento, produtividade e qualidade de frutos do meloeiro sob diferentes níveis de salinidade da água de irrigação e cobertura do solo. Mossoró: ESAM, 2002. 65p. Dissertação Mestrado 